\title{
Septum Volume and Food-Storing Behavior Are Related in Parids
}

\author{
Michael W. Shiflett, ${ }^{1}$ Kristy L. Gould, ${ }^{1}$ Tom V. Smulders, ${ }^{2}$ Timothy J. DeVoogd ${ }^{1}$ \\ ${ }^{1}$ Department of Psychology, Cornell University, Uris Hall, Ithaca, New York 14853 \\ ${ }^{2}$ Department of Neurobiology, Duke University Medical Center, Durham, North Carolina 27710
}

Received 20 September 2001; accepted 8 January 2002

\begin{abstract}
The hippocampal formation (HF) of food-storing birds is larger than non-storing species, and the size of the HF in food-storing Black-Capped Chickadees (Poecile atricapillus) varies seasonally. We examined whether the volume of the septum, a medial forebrain structure that shares reciprocal connections with the HF, demonstrates the same species and seasonal variation as has been shown in the HF. We compared septum volume in three parid species; non-storing Blue Tits (Parus caeruleus) and Great Tits (Parus major), and food-storing Black-Capped Chickadees. We found the relative septum volume to be larger in chickadees than in the non-storing species. We also
\end{abstract}

compared septum and nucleus of the diagonal band (NDB) volume of Black-Capped Chickadees at different times of the year. We found that the relative septum volume varies seasonally in food-storing birds. The volume of the NDB does not vary seasonally. Due to the observed species and seasonal variation, the septum, like the hippocampal formation of food-storing birds, may be specialized for some aspects of food-storing and spatial memory. () 2002 Wiley Periodicals, Inc. J Neurobiol 51: 215-222, 2002

Keywords: food storing; septum; hippocampus; chickadee; paridae

\section{INTRODUCTION}

Behaviors that rely on an accurate and extensive memory for spatial locations, such as homing in pigeons and food caching in some avian species, requires a functioning hippocampal formation (HF) (Sherry and Vaccarino, 1989; Bingman et al., 1995; Hampton and Shettleworth, 1996; Gagliardo et al., 1999; Strasser and Bingman, 1999). Furthermore, the $\mathrm{HF}$ is larger with respect to telencephalon in such species than in species that do not show these behaviors (Krebs et al., 1989; Healy and Krebs, 1992;

\footnotetext{
Correspondence to: M.W. Shiflett (mws14@cornell.edu).

Contract grant sponsor: National Institutes of Health; contract grant number: MH56093 (T.J.D.).

Contract grant sponsor: National Institutes of Health; contract grant number: MH12934 (M.W.S.).

(C) 2002 Wiley Periodicals, Inc.

Published online in Wiley InterScience (www.interscience.wiley.com). DOI 10.1002/neu.10054
}

Hampton et al., 1995; Rehkamper et al., 1995). In at least one food-storing species, the Black-Capped Chickadee (Poecile atricapillus), an increase in caching behavior in the Fall coincides with an increase in the volume and number of neurons in the HF (Smulders et al., 1995, 2000b), which is likely due to an increase in the survival of newly generated neurons in the HF (Barnea and Nottebohm, 1994, 1996).

The avian HF shares reciprocal connections with the septum, a set of forebrain nuclei consisting of the medial and lateral septum and the nucleus of the diagonal band (NDB) (Krayniak and Siegel, 1978a,b; Szekely and Krebs, 1996; Szekely, 1999). In birds, the septum is known to be involved in the regulation of aggression and courtship behavior (Cooper and Erickson, 1976; Goodson et al., 1999). This function is likely a result of the septum's connections with hypothalamic nuclei (Krayniak and Siegel, 1978b). The function of reciprocal connections between the hip- 

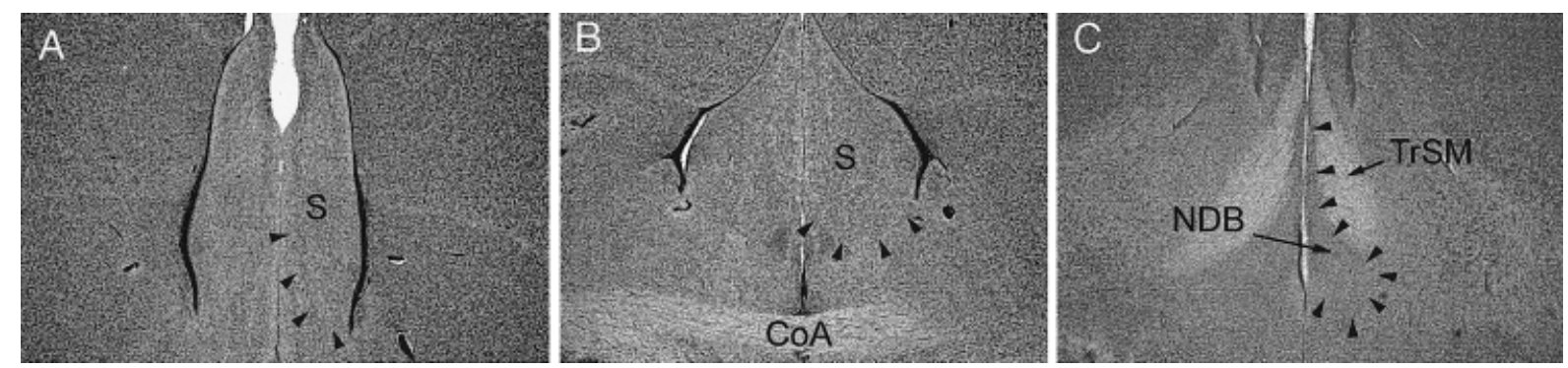

Figure 1 Photomicrographs of the septum of a Black-Capped Chickadee. Arrowheads indicate boundaries. (A) Anterior septum (S); (B) septum at the level of the anterior commisure; (C) nucleus of the diagonal band (NDB). ( $\mathrm{CoA}=$ anterior commisure; $\operatorname{TrSM}=$ septomesencephalic tract.)

pocampus and septum in birds is not known. However, in mammals, septo-hippocampal interactions are necessary for the acquisition and consolidation of spatial memory (Chrobak et al., 1989; Poucet et al., 1991; Chrobak and Napier, 1992; Poucet and Buhot, 1994; Walsh et al., 1998).

If the septum is also important for spatial memory in birds, then one prediction is that species selected for accurate and extensive spatial memory, as in the case of food-storing birds, will possess a larger septum relative to overall brain size. Alternatively, the septum, known to mediate species-specific social behaviors, may be involved in some aspects of behavior not related to memory. In the first experiment of this study, we examined whether differences in the volume of the septum exist between a storing species, the Black-Capped Chickadee, and two non-storing species from the same genus, Great Tits (Parus major), and Blue Tits (Parus caeruleus). In the second experiment, we examined septum volumes in BlackCapped Chickadees sampled at different times of the year to determine whether the volume of the septum varies seasonally in this species.

\section{METHODS}

\section{Experiment 1: Species Comparison of Septum Volume}

Subjects. Eight Black-Capped Chickadees (four males, four females) were captured in the Ithaca, NY area between March and April 1998 using mist nets and Potter's traps. Eight Great Tits (four males, four females) and seven Blue Tits (three males, four females) were captured in Brecht, Belgium during March 1998. Birds were taken into the laboratory on the day they were caught; age and sex were determined after perfusion. Age was determined based on the ossification of the skull: juvenile (skull not completely ossified) and adult (ossified skull). Unless otherwise noted, only adult birds were used for analysis.
Histology. Birds were anesthetized with a lethal dose of Chloropent (Fort Dodge Labs, Overland Park, Kansas) and transcardially perfused with $0.9 \%$ saline and $0.1 \%$ sodium nitrite in a $0.1 M$ sodium phosphate buffer solution ( $\mathrm{pH} 7.4$ ), followed by $4 \%$ paraformaldehyde in sodium phosphate buffer (PB). Each brain was removed immediately, postfixed for $1 \mathrm{~h}$ at $4^{\circ} \mathrm{C}$, and transferred to $30 \%$ sucrose in a $4 \%$ paraformaldehyde/PB solution for $2-3$ days at $4^{\circ} \mathrm{C}$ until the brain sank. The brains were embedded in $10 \%$ gelatin $/ 30 \%$ sucrose and stored in a $4 \%$ paraformaldehyde/PB solution for 2-3 days. The brains were then sliced coronally on a freezing microtome at $40 \mu \mathrm{m}$ and transferred to small vials filled with cryoprotectant. The vials were stored at $-20^{\circ} \mathrm{C}$ until they were mounted, stained with cresyl-violet, and coverslipped. Every sixth section was mounted and stained in this manner, with other sections being used for a separate immunohistochemical study.

\section{Volume Measurements.}

Septum and Nucleus of the Diagonal Band. Using a camera lucida mounted on a light microscope, line drawings of the septum and the NDB were made at $240 \mu \mathrm{m}$ intervals. The septum boundaries were defined as follows: The dorsal boundary of the septum coincided with the ventral boundary of the hippocampus; the lateral boundary was defined by the lateral ventricle; the ventral boundary in rostral sections was defined by the appearance of the septomesencephalic tract and in medial/caudal sections by the appearance of the anterior commisure, as well as changes in cell density (Fig. 1). The septomesencephalic tract defined the dorsal and lateral boundaries for the NDB, while ventral boundaries were delineated by a change in cell density. Medial boundaries were defined by the midline and appearance of the anterior preoptic nucleus. Boundaries were consistent across individuals and species. The experimenters were blind to the species and sex of the animal being measured. Line drawings of the septum and NDB were digitized and the surface area of each tracing measured on a Macintosh IIci using NIH Image 1.54. We calculated volumes of the septum and NDB by multiplying the surface area of each section by the sample interval distance and then summing the products.

Hippocampal Formation and Telencephalon. Sections were scanned with a video camera (COHU) and dig- 
itized on a Macintosh IIci using NIH Image 1.54. The area of the target structure was outlined and measured. We then calculated the volume by multiplying the surface area by the sample interval distance and then summing the products.

Statistical Analysis. To analyze the effect of several categorical variables (season, sex, age, storer vs. non-storer) on a single continuous variable such as the volume of a particular brain nucleus, we used the General Linear Model, which combines regression analysis and analysis of variance (Darlington and Smulders, 2001). This approach allows us to statistically control for covariates; in this case, we specified telencephalon volume (minus the target structure) as a covariate to examine the effect of different independent variables on the relative volume of the structure of interest, independent of changes in telencephalon volume. To ascertain the effect of food storing on target structure size, we assigned birds as either storers or non-storers and included this as a dichotomous fixed factor in the model. Sex of the bird was included as a dichotomous fixed factor as well. Significance is considered at $p<0.05$.

\section{Experiment 2: Seasonal Comparison of Septum Volume}

Subjects. Forty-eight Black-Capped Chickadees (17 juvenile, 31 adult) of both sexes ( 23 female, 25 male) were caught near Ithaca, NY, under State and Federal permits. These birds were part of an earlier study (Smulders et al., 1995, 2000b). Subjects were caught at six different times of the year, from October 1992 through December 1993. In the winter months, birds were caught with Potter's traps baited with food, and in the summer with song playback and mist nets. For each sample, multiple birds were typically caught on the same day from the same flock. Birds were taken into the laboratory on the day they were caught; age and sex were determined after perfusion. Age was determined based on the ossification of the skull: juvenile (skull not completely ossified) and adult (ossified skull). Unless otherwise noted, only adult birds were used for analysis.

Histology. Birds were anesthetized with a lethal dose of Chloropent (Fort Dodge Labs) and perfused transcardially with $0.8 \%$ saline and $10 \%$ formalin in $0.8 \%$ saline. The heads were then post-fixed in $10 \%$ formalin $/ 0.8 \%$ saline for at least 1 day, after which the brain was removed from the skull, weighed, and allowed to post-fix for at least another day in formalin/saline. The brain was then transferred to $10 \%$ formalin in $30 \%$ sucrose, until it sank (2 to 3 days). It was weighed again and embedded in $10 \%$ gelatin $/ 30 \%$ sucrose, which was hardened in $10 \%$ formalin $/ 30 \%$ sucrose. The brains were then sliced coronally on a freezing microtome at $40 \mu \mathrm{m}$ and transferred to microscope slides. Alternate sections were stained with cresyl-violet and coverslips were placed with Permount ${ }^{\circledR}$ (Fisher Scientific, Hampton, New Hampshire).
Volume Measurements. Volume measurements were conducted using the same structure boundaries and volume estimation methods as in Experiment 1. In this experiment however, we measured samples at an interval of $80 \mu \mathrm{m}$, while in the previous experiment we measured samples at $240 \mu \mathrm{m}$. It is likely that the smaller sampling interval will yield more accurate estimates of volume. However, since we are not comparing values from the two experiments, the different sampling intervals we used should have no influence on our results.

Statistical Analysis. As in Experiment 1, the General Linear Model was used, in this case to assess the effects of seasonality on target structure volume. We divided the year into six time periods: February, April, June, August, October, and December. Birds were assigned to one of the six groups based on their date of capture, and this value was included as a fixed factor in the model. Sex of the bird was included in the model as a dichotomous fixed factor. Telencephalon volume (minus target structure) was included in the model as a covariate. For post-hoc tests, the Fisher Least Significant Difference (LSD) test was performed and significance is considered at $p<0.05$.

\section{RESULTS}

\section{Experiment 1: Species Comparisons of Septum Volume}

Septum. With Septum volume as the dependent variable, food-storing vs. non-storing as a dichotomous independent variable, and telencephalon volume (excluding septum) as a covariate, we found a significant effect of food storing on septum volume $[F(1,23)$ $=4.67 ; p=0.043]$, and a significant effect of telencephalon volume $[F(1,23)=6.86 ; p$ $=0.016]$ on septum volume. Black-Capped Chickadees, a food-storing species, have a larger septum than Great Tits and Blue Tits, two species from the same genus that do not store food (Fig. 2). This species difference exists independent of the significant correlation between septum and telencephalon volumes.

Hippocampal Formation. With $\mathrm{HF}$ volume as an independent variable, food-storing versus non-storing as a dichotomous independent variable and telencephalon (excluding HF) as a covariate, we found a significant effect of food-storing on relative HF volume and a significant effect of telencephalon on HF volume $[F(1,23)=6.134 ; p=0.022]$. Food-storing Black-Capped Chickadees have a larger HF than two closely related non-storing species, Great Tits and Blue Tits. We performed a partial correlation of HF and septum volume, controlling for telencephalon size 


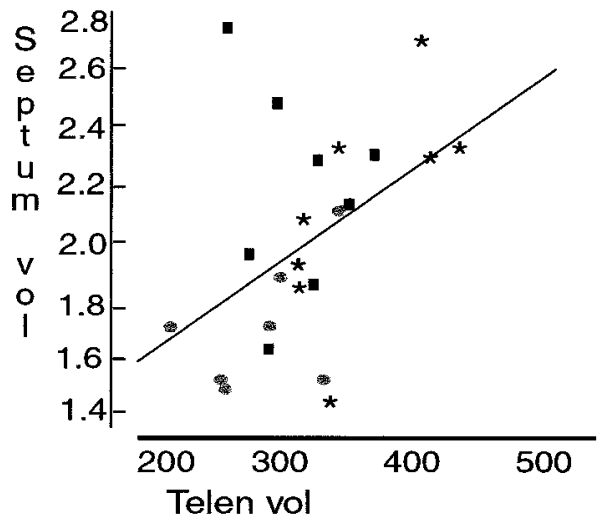

Figure 2 Scatterplot of septum volume (Y axis) against telencephalon ( $\mathrm{X}$ axis) for three species of paridae. Black squares denote food-storing Black-Capped Chickadees; gray circles denote non-storing Blue Tits; asterisks denote non-storing Great Tits. The majority of cases of BlackCapped Chickadees fall above the regression line, while the majority of cases of the two non-storing species fall below the regression line.

(excluding HF and septum) and found a significant correlation [Partial correlation coefficient $=0.5641 ; p$ $=0.006]$. However, when food-storing was controlled for statistically, the partial correlation between septum and HF volume became non-significant [Partial correlation coefficient $=0.365 ; p=0.10]$, suggesting that septum and HF volume are not correlated independent of the observed co-variation between both structures related to food storing.

\section{Experiment 2: Seasonal Comparisons of Septum Volume}

Septum. We found a significant effect of time of year on septum volume $[F(5,28)=3.702 ; p=0.019]$, but no effect of sex $[F(1,28)=0.221$; NS $]$, or telencephalon volume (excluding septum) $[F(1,28)$ $=1.02 ; \mathrm{NS}]$, nor was there an interaction of season and sex $[F(4,28)=0.73$; NS $]$. Post-hoc tests compared the mean of the October group to groups from other months, since in prior work on this tissue the HF was larger in the October sample than in other samples. The septum from the October group was significantly different from the February, June, and August groups [Fisher LSD, Oct $>$ Feb, $p=0.014$; Oct $>$ Jun, $p=0.020$; Oct $>$ Aug, $p=0.037]$. Adult black-capped chickadees show seasonal variation in relative septum volume, because the septum is larger in October than in February, June, and August (Fig. 3).

For the months of June, August, and October, we were able to differentiate adult from juvenile black-

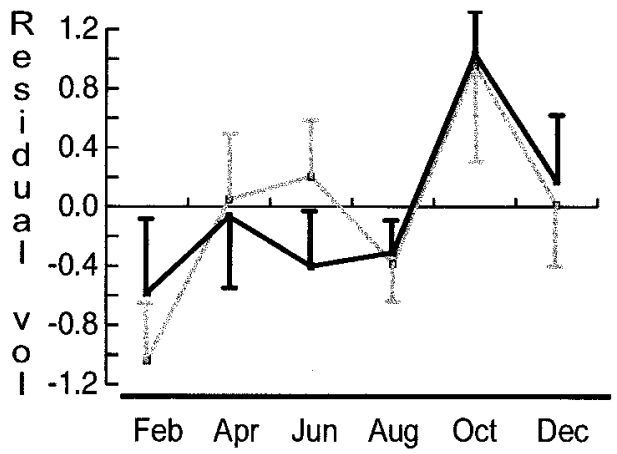

Figure 3 Mean residual values ( \pm S.E.M.) of the septum (black line) and hippocampal formation (HF) (gray line) for Black-Capped Chickadees, taken from the regression of either septum or HF against telencephalon volume. Mean values are plotted for six 2-month periods. The residual volume for both the septum and HF is highest in October.

capped chickadees. For these months, we examined the effect of age on septum volume by including it as a dichotomous fixed factor (juvenile vs. adult), along with season in the General Linear Model, while controlling for telencephalon volume by including it as a covariate. We found a significant effect of age $[F(1$, $30)=9.92, p<0.01]$, as well as a significant effect of season $[F(2,30)=8.12, p<0.01]$, but no interaction of age and season $[F(2,30)=0.60$; NS $]$ (Fig. 4). Adult black-capped chickadees have a larger septum relative to telencephalon volume than do juvenile chickadees.

Hippocampal Formation. We performed a partial correlation between the volume of the HF and the septum, controlling for telencephalon volume (ex-

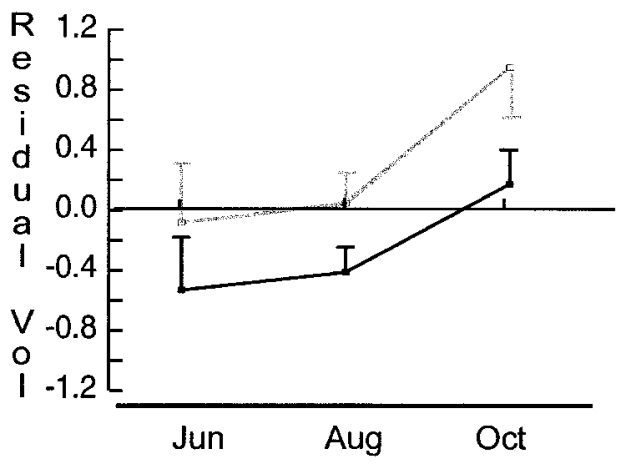

Figure 4 Mean residual values ( \pm S.E.M.) of the septum for adult (gray line) and juvenile (black line), taken from the regression of septum against telencephalon volume. The residual values are plotted for the months of June, August, and October. While adults show a greater overall residual septum volume, the pattern of seasonal variation for both adults and juveniles remains the same. 


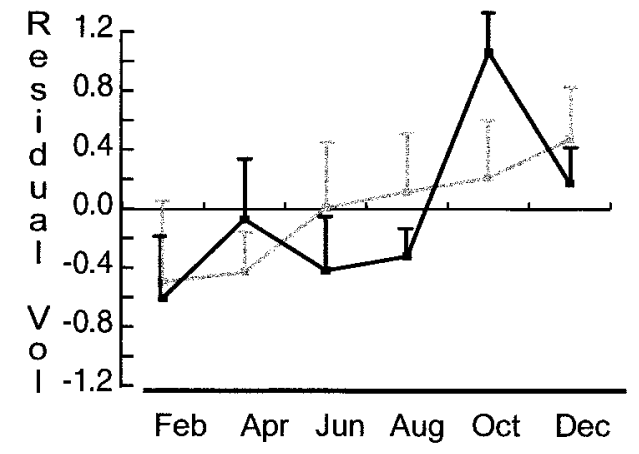

Figure 5 Mean residual values ( \pm S.E.M.) of the septum (black line) and nucleus of the diagonal band (NDB) (gray line) for Black-Capped Chickadees, taken from the regression of either septum or NDB against telencephalon volume. Mean values are plotted for six 2-month periods. A peak in residual volume exists for the septum, but not the NDB.

cluding HF and septum) and found a significant correlation [Partial correlation coefficient $=0.3864 ; p$ $=0.042]$. However, when season of capture was also controlled for statistically, the correlation between HF and septum volume became non-significant [Partial correlation coefficient $=0.2813, p=0.15$ ], suggesting that septum and $\mathrm{HF}$ volume are not correlated independent of the observed co-variation between both structures related to seasonality.

Nucleus of the Diagonal Band. With NDB as the dependent variable and telencephalon, sex and time of year as independent variables, we found no effect of telencephalon $[F(1,28)=1.76 ; \mathrm{NS}]$, sex $[F(1,28)$ $=1.13 ; \mathrm{NS}]$ or season $[F(5,28)=0.93 ; \mathrm{NS}]$ on relative NDB volume (Fig. 5).

\section{DISCUSSION}

The results of this study demonstrate that the neural specializations of food-storing birds are not confined to the HF, but also include the septum, a set of forebrain nuclei sharing reciprocal connections with the HF. Species comparisons demonstrate a larger relative septum volume in food-storing Black-Capped Chickadees versus closely related but non-storing Blue Tits and Great Tits. Furthermore, the septum volume in Black-Capped Chickadees increases during the fall when chickadees exhibit peak caching behavior. This seasonal increase in structure volume is not a general phenomenon across all regions of the brain since the NDB, which sends projections to the HF, does not show seasonal changes in volume. In both the food-storing and non-storing populations sampled, the size of the septum and HF show a high degree of correlation independent of any variation in overall telencephalon size. However this correlation is not independent of such factors as seasonality or food storing. It is unknown whether these factors act independently on the size of the septum and HF, or whether sizes changes in one structure result in changes in the other structure.

As has been shown previously (Smulders et al., 1995), the HF is smaller in juveniles than in adult chickadees. We were not able to distinguish between juvenile and adults in the chickadees that made up our samples for the months of December, February, and April. Therefore, the lower average septum volume observed in December and February could potentially be a result of including juvenile birds in these samples in which these structures had not yet achieved adult volume. However, at the times when adult and juvenile chickadees can be distinguished (i.e., June, August, and October), we find that the relative volumes of the septum and HF are greater in October relative to June and August for both adults and juveniles. Therefore the seasonal increase in relative septum volume in October is independent of any effect of age on septum volume.

The mechanisms responsible for seasonal plasticity in septum volume are unknown. Seasonal changes in the HF have been shown to be associated with an increase in neuron number (Smulders et al., 2000b), probably due to increased survival of newly generated neurons (Barnea and Nottebohm, 1994, 1996). An increase in cell number might also be responsible for volume changes in the septum. Alternatively, the increase in volume could be a result of an increase in the size of neurons already present in the septum. A count of cells within the septum would distinguish between these alternative hypotheses.

A number of intrinsic and extrinsic factors may be responsible for seasonal variation in the septum and HF. Extrinsic factors such as temperature, day length, or onset of food storing behavior, or intrinsic factors such as hormone fluctuations and neurotrophin actions, or some interaction of factors may be responsible for seasonal neural plasticity. The actual act of storing food has been shown to trigger an increase in hippocampal volume in juvenile Marsh Tits compared to that of juveniles not allowed to store food (Clayton, 1994, 1995; Chittka and Geiger, 1995), however, this does not appear to be the case for adult birds (Cristol, 1996). Other extrinsic factors, such as light and temperature, have been shown to cause changes in performance on spatial memory tasks, and have not been associated with any changes in the volume of the HF (Krebs et al., 1995; Shettleworth et al., 1995). This 
dissociation between behavioral and brain changes may be explained by the artificial and stressful conditions of a laboratory setting (Smulders et al., 2000a). Future studies could examine in more detail the factors that may trigger seasonal changes, and whether these changes act on the septum as well.

In addition to seasonal changes in septum volume, comparisons between the food-storing chickadee and two non-storing birds within the same genus, the Great Tit and Blue Tit, reveal a larger relative septum and HF volume in chickadees than the other two species (Healy and Krebs, 1992, 1996; Hampton et al., 1995). Since there are no non-storing species of Paridae in North America and we wanted to keep our comparisons within the same genus, we used nonstoring Parid species from Europe. Because of this, our comparison of food-storing and non-storing species is also a comparison of species from different habitats. While it remains a possibility that differences in habitat are responsible for the observed species differences in septum volume, we can find no obvious reason why this should be the case. A comparison of storing and non-storing paridae from the same habitat would resolve this issue.

If the septum and HF indeed function together in some aspects of spatial memory processing, a foodstoring bird may have more neurons in both structures or there may be more connections between the two structures associated with the demands of food caching on spatial memory. Indeed, the septum in rats is important for spatial memory, as shown by experiments in which it has been lesioned or inactivated (Bostock et al., 1988; Chrobak et al., 1989; Poucet et al., 1991; Poucet and Buhot, 1994; Walsh et al., 1998).

One important function of the septum in mammals is to establish the theta rhythm, a $4-10 \mathrm{~Hz}$ rhythmical pattern of electrical activity within the HF. This activity is thought to be correlated with the acquisition of sensory information by the HF and may be important in the reinforcement and consolidation of memories (Mitchell et al., 1982; Stewart and Fox, 1990; Chrobak and Napier, 1992). The septum also contains cholinergic cells that project to the HF. Acetylcholine is thought to regulate the theta rhythm in mammals and have a modulatory affect on cell function in the HF (Monmaur et al., 1997; Keita et al., 2000). A theta-like pattern of activity was recently found in homing pigeons (Siegel et al., 2000); whether the septum is involved in generating this activity in pigeons is not known.

The NDB, which is a separate part of the septal complex, is found in both birds and mammals. Cells in both the NDB and medial septum give rise to the septo-hippocampal pathway that sends both cholinergic and GABAergic projections to the HF (Amaral and Kurz, 1985; Wainer et al., 1985). The fact that the NDB did not show seasonal plasticity in the birds we investigated suggests that its role is different from that of the rest of the septum and that it may not be involved in seasonal spatial memory behavior.

The inference that variation in the size of the septum reflects some role in the processing of spatial memory is complicated by the fact that the septum is involved in a number of diverse behaviors. It is possible that variation in the size of the septum reflects some species-specific behaviors not related to memory. One proposed function of the avian septum is to regulate behavior based on the animal's internal state (Cooper and Erickson, 1976; Font et al., 1998; Goodson et al., 1999). Since food-storing behavior is sensitive to the internal state of the animal as well as the social context (Lucas and Walter, 1991; Lahti and Rytkonen, 1996), it is possible that the larger septum in food-storing Black-Capped Chickadees is somehow related to the modulation of food-storing behavior. Furthermore, the social organization of BlackCapped Chickadees varies seasonally, as chickadees form stable flocks in the winter months (Smith and Van Buskirk, 1988). Seasonal variation in septum volume in Black-Capped Chickadees may be related to this seasonal change in social organization. It is therefore possible that our findings may reflect the septum's role in modulating species-specific behaviors independent of any role in processing memory.

Our results demonstrate that the neuroanatomical specialization of food-storing birds includes size increases in both the HF and septum. The septum is larger in food-storing species than in closely related non-storing species. Among food-storing BlackCapped Chickadees, the septum, like the HF, increases in volume in the fall coincident with the onset of food-storing behavior. This evidence suggests that the memory specialization in food-storing birds may be attributable in part to an alteration of the interactivity between the septum and HF.

We thank Mike Kalogiannis for his work on various aspects of this project, as well as the Laboratory of Cytology and Histology at the University of Antwerp (RUCA) for help preparing the Blue Tit and Great Tit tissue.

\section{REFERENCES}

Amaral DG, Kurz J. 1985. An analysis of the origins of the cholinergic and non-cholinergic septal projections to the 
hippocampal formation of the rat. J Comp Neurol 240: 37-59.

Barnea A, Nottebohm F. 1994. Seasonal recruitment of hippocampal neurons in adult free-ranging black-capped chickadees. Proc Natl Acad Sci USA 91:11217-11221.

Barnea A, Nottebohm F. 1996. Recruitment and replacement of hippocampal neurons in young and adult chickadees: an addition to the theory of hippocampal learning. Proc Natl Acad Sci USA 93:714-718.

Bingman VP, Jones TJ, Strasser R, Gagliardo A, Ioale P. 1995. Homing pigeons, hippocampus and spatial cognition. In: Alleva E, Fasolo A, Lipp H-P, Nadel L, Ricceri L, editors. pp. 207-224. Nato ASI series D: behavioural and social sciences; behavioural brain research in naturalistic and semi-naturalistic settings. Dordrecht: Kluwer.

Bostock E, Gallagher M, King RA. 1988. Effects of opioid microinjection into the medial septal area on spatial memory in rats. Behav Neurosci 102:643-650.

Chittka L, Geiger K. 1995. Honeybee long-distance orientation in a controlled environment. Ethology 99:117-126.

Chrobak JJ, Napier TC. 1992. Antagonism of GABAergic transmission within the septum disrupts working/episodic memory in the rat. Neuroscience 47:833-841.

Chrobak JJ, Stackman RR, Walsh TJ. 1989. Intraseptal administration of muscimol produces dose-dependent memory impairments in the rat. Behav Neural Biol 52: 357-369.

Clayton NS. 1994. The role of age and experience in the behavioural development of food-storing and retrieval in marsh tits, Parus palustris. Anim Behav 47:1435-1444.

Clayton NS. 1995. Development of memory and the hippocampus: comparison of food-storing and non-storing birds on a one-trial associative memory task. Neuroscience 15:2796-2807.

Cooper RL, Erickson CJ. 1976. Effects of septal lesions on the courtship behavior of male ring doves (Streptopelia risoria). Horm Behav 7:441-450.

Cristol DA. 1996. Food storing does not affect hippocampal volume in experienced adult willow tits. Behav Brain Res 81:233-236.

Darlington RB, Smulders TV. 2001. Problems with residual analysis. Anim Behav 62:599-602.

Font C, Lanuza E, Martinez-Marcos A, Hoogland PV, Martinez-Garcia F. 1998. Septal complex of the telencephalon of lizards: III. Efferent connections and general discussion. J Comparative Neurol 401:525-548.

Gagliardo A, Ioale P, Bingman VP. 1999. Homing in pigeons: the role of the hippocampal formation in the representation of landmarks used for navigation. J Neurosci 19:311-315.

Goodson JL, Eibach R, Sakata J, Adkins-Regan E. 1999. Effect of septal lesions on male song and aggression in the colonial zebra finch (Taeniopygia guttata) and the territorial field sparrow (Spizella pusilla). Behav Brain Res 98:167-180.

Hampton R, Shettleworth S. 1996. Hippocampal lesions impair memory for location but not color in passerine birds. Behav Neurosci 110:831-835.
Hampton RR, Sherry DF, Shettleworth SJ, Khurgel M, Ivy G. 1995. Hippocampal volume and food-storing behavior are related in parids. Brain Behav Evol 45:54-61.

Healy SD, Krebs JR. 1992. Food storing and the hippocampus in corvids: amount and volume are correlated. Proc $\mathrm{R}$ Soc Lond [Biol] 248:241-245.

Healy SD, Krebs JR. 1996. Food storing and the hippocampus in paridae. Brain Behav Evol 47:195-199.

Keita MS, Frankel-Kohn L, Bertrand N, Lecanu L, Monmaur P. 2000. Acetylcholine release in the hippocampus of the urethane anaesthetized rat positively correlates with both peak theta frequency and relative power in the theta band. Brain Res 887:323-334.

Krayniak PF, Siegel A. 1978a. Efferent connections of the hippocampus and adjacent regions in the pigeon. Brain Behav Evol 15:372-388.

Krayniak PF, Siegel A. 1978b. Efferent connections of the septal area in the pigeon. Brain Behav Evol 15:389-404.

Krebs JR, Sherry DF, Healy SD, Perry VH, Vaccarino AL. 1989. Hippocampal specialization of food-storing birds. Proc Natl Acad Sci USA 86:1388-1392.

Krebs JR, Clayton NS, Hampton RR, Shettleworth SJ. 1995. Effects of photoperiod on food-storing and the hippocampus in birds. NeuroReport 6:1701-1704.

Lahti K, Rytkonen S. 1996. Presence of conspecifics, time of day and age affect willow tit food hoarding. Anim Behav 52:631-636.

Lucas JR, Walter LR. 1991. When should chickadees hoard food? Theory and experimental results. Anim Behav 41: 579-601.

Mitchell SJ, Rawlins JA, Steward O, Olton DS. 1982. Medial septal area lesions disrupt theta rhythm and cholinergic staining in medial entorhinal cortex, and produce impaired radial arm maze behavior in rats. J Neurosci 2:292-302.

Monmaur P, Collet A, Puma C, Frankel-Kohn L, Sarif A. 1997. Relations between acetylcholine release and electrophysiological characteristics of theta rhythm: a microdialysis study in the urethane-anesthetized rat hippocampus. Brain Res Bull 42:141-146.

Poucet B, Buhot MC. 1994. Effects of medial septal or unilateral hippocampal inactivations on reference and working spatial memory in rats. Hippocampus 4:315321.

Poucet B, Herrmann T, Buhot M-C. 1991. Effects of shortlasting inactivations of the ventral hippocampus and medial septum on long-term and short-term acquisition of spatial information in rats. Behav Brain Res 44:53-65.

Rehkamper G, Frahm HD, Mann MD. 1995. Brain composition and ecological niches in the wild or under manmade conditions (domestication). In: Alleva E, editor. pp. 83-104. Behavioural brain research in naturalistic and semi-naturalistic settings. Dordrecht: Kluwer.

Sherry DF, Vaccarino AL. 1989. Hippocampus and memory for food caches in black-capped chickadees. Behav Neurosci 103:308-318.

Shettleworth SJ, Hampton RR, Westwood RP. 1995. Effects of season and photoperiod on food-storing by black- 
capped chickadees Parus atricapillus. Anim Behav 49: 989-998.

Siegel JJ, Nitz D, Bingman VP. 2000. Hippocampal theta rhythm in awake, freely moving homing pigeons. Hippocampus 10:627-631.

Smith DC, Van Buskirk J. 1988. Winter territoriality and flock cohesion in the black-capped chickadee Parus atricapillus. Anim Behav 36:466-476.

Smulders TV, Sasson AD, DeVoogd TJ. 1995. Seasonal variation in hippocampal volume in a food-storing bird, the black-capped chickadee. J Neurobiol 27:15-25.

Smulders TV, Casto JM, Nolan V, Ketterson ED, DeVoogd TJ. 2000a. Effects of captivity and testosterone on the volumes of four brain regions in the dark-eyed Junco (Junco hyemalis). J Neurobiol 43:244-253.

Smulders TV, Shiflett MW, Sperling AJ, DeVoogd TJ. 2000b. Seasonal changes in neuron numbers in the hippocampal formation of a food-hoarding bird: the blackcapped chickadee. J Neurobiol 44:414-422.
Stewart M, Fox SE. 1990. Do septal neurons pace the hippocampal theta rhythm. Trends Neurosci 13:163-168. Strasser R, Bingman VP. 1999. The effects of hippocampal lesions in homing pigeons on a one-trial food association task. J Comp Physiol [A] 185:583-590.

Szekely AD. 1999. The avian hippocampal formation: subdivisions and connectivity. Behav Brain Res 98:219-225.

Szekely AD, Krebs JR. 1996. Efferent connectivity of the hippocampal formation of the zebra finch (Taeniopygia guttata): an anterograde pathway tracing study using Phaseolus vulgaris leucoagglutinin. J Comp Neurol 368: 198-214.

Wainer BH, Levey AI, Rye DB, Mesulam MM, Mufson EJ. 1985. Cholinergic and noncholinergic septohippocampal pathways. Neurosci Lett 54:45-52.

Walsh TJ, Gandhi C, Stackman RW. 1998. Reversible inactivation of the medial septum or nucleus basalis impairs working memory in rats: a dissociation of memory and performance. Behav Neurosci 112:1114-1124. 